ISSN 0103-8478

\title{
Controle da podridão abacaxi da cana-de-açúcar por meio da pulverização de fungicidas em rebolos no sulco de plantio
}

\author{
Control of pineapple disease of sugarcane through in-furrow \\ fungicide spray application on seedpieces
}

\author{
Roberto Giacomini Chapola, II Gustavo Akio OgasawaraII Bruno Jans ${ }^{\text {II }}$ \\ Nelson Sidnei Massola Junior ${ }^{\text {II }}$
}

RESUMO

A podridão abacaxi da cana-de-açúcar, causada pelo fungo Thielaviopsis paradoxa, pode causar quedas de até $50 \%$ na brotação e de $42 \%$ na produtividade de colmos. O objetivo deste trabalho foi avaliar o controle da doença por meio da pulverização de fungicidas em rebolos no sulco de plantio. Para isso, foram instalados dois experimentos em casa de vegetação e um no campo. O substrato e o solo foram infestados com o patógeno antes do plantio da canade-açúcar $e$ os fungicidas foram aplicados nos rebolos imediatamente após o plantio, com um pulverizador costal pressurizado com $\mathrm{CO}_{2}$. A pulverização dos rebolos no sulco de plantio mostrou-se eficaz no controle da podridão abacaxi com determinados fungicidas, trazendo incrementos na brotação e proporcionando recuperação de até $12 \%$ na produtividade. Dentre os tratamentos testados, os fungicidas piraclostrobina + epoxiconazol; piraclostrobina e propiconazol mostraram bom potencial no controle da doença.

Palavras-chave: Thielaviopsis paradoxa, Saccharum spp., controle químico, brotação.

\section{ABSTRACT}

Sugarcane pineapple disease, caused by the fungus Thielaviopsis paradoxa, can cause germination and yield decreases of up to $50 \%$ and $42 \%$, respectively. The aim of this research was to assess the control of this disease through infurrow fungicide application on seedpieces. Two experiments were installed in greenhouse and one under field conditions with this purpose. The substrate and the soil were infested with the pathogen before the sugarcane planting and the fungicides were sprayed on seedpieces immediately after the planting with a $\mathrm{CO}_{2}$ backpack sprayer. Seedpieces in-furrow spraying was effective in controlling the pineapple disease with certain fungicides, providing up to $12 \%$ yield recovery. Among the tested treatments, the fungicides pyraclostrobin + epoxiconazole; pyraclostrobin and propiconazole showed good potential for pineapple disease control.

Key words: Thielaviopsis paradoxa, Saccharum spp., chemical control, germination.

\section{INTRODUÇÃO}

O Brasil é o maior produtor mundial de cana-de-açúcar, com uma área estimada em 8,5 milhões de hectares e produtividade média de colmos de 70,3t ha ${ }^{-1}$ (CONAB, 2012). Entretanto, na safra 2011/12, houve queda de $11,8 \%$ na produtividade; dentre as principais causas estão a diminuição dos insumos aplicados e a redução do manejo da cultura, devido à descapitalização de muitos produtores (CONAB, 2011). Com a cultura debilitada, intensificam-se problemas com doenças, que, segundo OERKE (2006), podem causar danos de até $16 \%$. Por isso, a intensificação da produção agrícola torna-se mais difícil sem uma concomitante intensificação no controle de doenças.

A podridão abacaxi da cana-de-açúcar, causada pelo fungo Thielaviopsis paradoxa, fase assexuada de Ceratocystis paradoxa, pode reduzir em até $50 \%$ a brotação e em até $42 \%$ a produtividade de colmos (BEGUM et al., 2008). O patógeno está presente no solo e pode infectar a cana-de-açúcar logo após o plantio, através de cortes ou ferimentos

\footnotetext{
IDepartamento de Biotecnologia e Produção Vegetal e Animal (DBPVA), Centro de Ciências Agrárias (CCA), Universidade Federal de São Carlos (UFSCAR), 13600-970, Araras, SP, Brasil. E-mail: chapola@cca.ufscar.br. Autor para correspondência.

IDepartamento de Fitopatologia e Nematologia (LFN), Escola Superior de Agricultura “Luiz de Queiroz” (ESALQ), Universidade de São Paulo (USP), Piracicaba, SP, Brasil.
} 
existentes nos rebolos. Tal fato é particularmente importante, uma vez que os colmos são seccionados por ocasião do plantio, oferecendo portas de entrada para o fungo (RAID, 2012). O plantio mecanizado, apesar de oferecer vantagens econômicas sobre o sistema manual, proporciona maior quantidade de danos nos rebolos, que são colhidos mecanicamente (SERAFIM et al., 2013). Isso, aliado à possibilidade de plantios que adentrem o período frio e seco do ano, gera condições favoráveis à podridão abacaxi, exigindo a adoção de medidas de manejo, como a utilização de fungicidas.

Diversos trabalhos comprovam a eficiência de fungicidas no controle da podridão abacaxi (HILTON et al., 1971; COMSTOCK et al., 1984; RAID, 1990; RAID, et al., 1991; FERREIRA et al., 2008). Estudos sobre tecnologia de aplicação mostraram que a pulverização de determinados fungicidas sobre os rebolos, assim como a imersão dos rebolos na calda (método utilizado anteriormente), tem efeito contra a doença (RAID, 1990; FERREIRA et al., 2008).

Considerando a importância da cultura da cana-de-açúcar para o Brasil e a viabilidade da aplicação de fungicidas no plantio, o objetivo deste trabalho foi avaliar o controle da podridão abacaxi por meio da pulverização de fungicidas em rebolos no sulco de plantio.

\section{MATERIAL E MÉTODOS}

Foram conduzidos dois experimentos em casa de vegetação e um no campo. Os experimentos em casa de vegetação foram instalados em junho de 2008 e em julho de 2009, ambos em Piracicaba (SP); o ensaio de campo foi instalado em junho de 2009, em Araras (SP). Pela classificação de Köppen, o clima de ambos os municípios é do tipo Cwa mesotérmico, com verões quentes e úmidos, e inverno seco.

Os ensaios foram instalados no inverno, quando as baixas temperaturas são favoráveis à doença. Durante a condução do primeiro ensaio em casa de vegetação, a temperatura média foi de $18,1^{\circ} \mathrm{C}$, enquanto que, durante a condução do segundo, foi de 20,7C (CIIAGRO, 2013). As temperaturas médias e as precipitações pluviométricas mensais ocorridas durante o ensaio de campo são apresentadas na tabela 1 .

Nos três ensaios, foi utilizado um isolado do fungo T. paradoxa, obtido em área de produção comercial, pertencente a uma unidade agroindustrial da região de Ribeirão Preto (SP). Para os ensaios em casa de vegetação, o fungo foi cultivado em placas contendo meio de cultura BDA durante cinco dias.
Tabela 1 - Temperatura média e precipitação pluviométrica mensal em Araras (SP) ${ }^{1}$, durante o período de junho de 2009 a julho de 2010.

\begin{tabular}{lcc}
\hline Mês/ano & Temperatura média $\left({ }^{\circ} \mathrm{C}\right)$ & Precipitação $(\mathrm{mm})$ \\
\hline Junho/09 & 16,4 & 61,0 \\
Julho/09 & 18,8 & 55,6 \\
Agosto/09 & 19,7 & 98,2 \\
Setembro/09 & 22,1 & 128,4 \\
Outubro/09 & 22,7 & 96,0 \\
Novembro/09 & 25,8 & 132,2 \\
Dezembro/09 & 24,1 & 330,6 \\
Janeiro/10 & 24,4 & 554,8 \\
Fevereiro/10 & 25,0 & 159,2 \\
Março/10 & 24,6 & 73,6 \\
Abril/10 & 22,1 & 53,6 \\
Maio/10 & 19,1 & 20,8 \\
Junho/10 & 17,9 & 19,0 \\
Julho/10 & 17,9 & 44,4 \\
\hline
\end{tabular}

${ }^{1}$ Fonte: Dados climatológicos - Centro de Ciências Agrárias, Universidade Federal de São Carlos. Disponível em: http://www.cca.ufscar.br/servicos/dados-climatologicos/

Após esse período, preparou-se uma suspensão de esporos por meio da adição de água destilada esterilizada às placas e raspagem das colônias com um pincel de cerdas macias. A suspensão foi calibrada em hemacitômetro e ajustada para $10^{6}$ esporos $\mathrm{mL}^{-1}$. Como substrato para o plantio da cana-de-açúcar, utilizouse uma mistura de solo, areia e esterco de gado na proporção de 3:3:1, esterilizada em autoclave. Após a distribuição do substrato em bandejas plásticas (6kg bandeja $^{-1}$ ), incorporou-se a suspensão de esporos com auxílio de um pulverizador manual (YADAHALLI et al., 2007), em volume suficiente para proporcionar concentração de $10^{3}$ esporos $\mathrm{g}^{-1}$ de substrato. Segundo MOUTIA \& SAUMTALLY (1999), tal concentração está dentro da faixa encontrada em solos naturalmente infestados.

Para a infestação do solo no ensaio de campo, o patógeno foi cultivado em quatro erlenmeyers, cada um com $500 \mathrm{~mL}$ de meio líquido a base de batata e dextrose. Após cinco dias de incubação a $25^{\circ} \mathrm{C}$ e agitação de $80 \mathrm{rpm}$ em agitador orbital, o meio foi filtrado em gaze e a suspensão foi calibrada em hemacitômetro e ajustada para $10^{6}$ esporos $\mathrm{mL}^{-1}$. Após a sulcação, a suspensão foi pulverizada nas paredes dos sulcos com um pulverizador costal manual (FERREIRA et al., 2008), proporcionando concentração de 9x10 esporos $\mathrm{m}^{-2}$.

Os rebolos foram coletados manualmente e obtidos do terço médio de colmos com idade de 10 meses. Optou-se pela variedade RB72454, suscetível 
à podridão abacaxi (GHELLER et al., 2002). Em casa de vegetação, foram plantados três rebolos de duas gemas, totalizando seis gemas por bandeja. Foram aplicados dez tratamentos no primeiro ensaio e oito no segundo, além de duas testemunhas não tratadas com fungicidas, uma plantada em substrato infestado e outra em substrato não infestado (Tabela 2). Os experimentos foram estabelecidos no delineamento inteiramente casualizado, com quatro repetições.

No ensaio de campo, foram utilizados rebolos de três a quatro gemas e o plantio foi realizado em uma densidade de 12 a 15 gemas $\mathrm{m}^{-1}$. Foram aplicados oito tratamentos, além de uma testemunha não tratada (Tabela 2). As parcelas consistiram de quatro sulcos de $10 \mathrm{~m}$, com espaçamento de $1,4 \mathrm{~m}$ entre linhas, e o delineamento experimental foi o de blocos ao acaso, com quatro repetições. Nos três ensaios, os fungicidas foram aplicados sobre os rebolos com um pulverizador costal pressurizado com $\mathrm{CO}_{2}$ (RAID, 1990), em um volume de calda correspondente a 150L ha-1; em seguida, os rebolos foram cobertos com substrato/solo.

Assim como realizado por RAID (1990), RAID et al. (1991) e FERREIRA et al. (2008), a intensidade da podridão abacaxi foi avaliada indiretamente pela brotação e desenvolvimento inicial das plantas, processos afetados pela doença. Em casa de vegetação, foram avaliadas: a porcentagem de brotação [(número de brotos/6)*100], em que 6 corresponde ao número de gemas plantadas em cada parcela; e as massas frescas da parte aérea e das raízes, todas aos 45 dias após o plantio.

No ensaio de campo, aos 90 dias após o plantio, determinaram-se o número de plantas $\mathrm{m}^{-1} \mathrm{e}$ a massa fresca da parte aérea, esta última obtida pela coleta da parte aérea presente em um metro central de um dos sulcos centrais de cada parcela, e pesagem em balança digital. Treze meses após o plantio, avaliaram-se: a produtividade de colmos (TCH), em t ha $^{-1}$, por meio de biometria (GHELLER et al., 1999); a concentração de açúcares totais recuperáveis (ATR), em $\mathrm{kg} \mathrm{ha} \mathrm{a}^{-1}$, obtido pelo envio de um feixe de dez colmos para o Laboratório de Análise e Simulação Tecnológica, localizado em Araras (SP), e pertencente ao Departamento de Tecnologia Agroindustrial e Socioeconomia Rural, da Universidade Federal de São Carlos; e o rendimento em açúcar (TAH), em t ha-1, obtido pela multiplicação das variáveis TCH e ATR e divisão do resultado por 1000 .

Os dados foram submetidos à análise de variância e as médias dos tratamentos foram comparadas com as médias da testemunha, utilizandose o Teste de Dunnett a 5\% de significância. Em casa de vegetação, os tratamentos foram comparados à testemunha plantada em substrato infestado.

Tabela 2 - Tratamentos aplicados e sua presença nos ensaios de campo e casa de vegetação.

\begin{tabular}{|c|c|c|c|c|c|}
\hline \multirow{2}{*}{ Siglas } & \multirow{2}{*}{ Tratamentos } & \multirow{2}{*}{$\begin{array}{l}\text { Doses } \\
\left(\mathrm{L} \mathrm{ha}^{-1}\right)\end{array}$} & \multicolumn{3}{|c|}{ 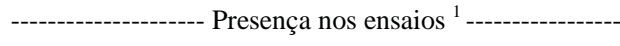 } \\
\hline & & & Casa de vegetação 1 & Casa de vegetação 2 & Campo \\
\hline $\mathrm{T} 1$ & Substrato/solo infestado e sem aplicação de fungicidas ${ }^{2}$ & - & + & + & + \\
\hline $\mathrm{T} 2$ & Substrato/solo não infestado e sem aplicação de fungicidas ${ }^{2}$ & - & + & + & - \\
\hline PE0,25 & Piraclostrobina + epoxiconazol & 0,25 & + & - & - \\
\hline PE0,50 & Piraclostrobina + epoxiconazol & 0,50 & + & - & - \\
\hline PE0,60 & Piraclostrobina + epoxiconazol & 0,60 & - & + & + \\
\hline PE0,75 & Piraclostrobina + epoxiconazol & 0,75 & + & - & - \\
\hline PE0,80 & Piraclostrobina + epoxiconazol & 0,80 & - & + & + \\
\hline PE1,00 & Piraclostrobina + epoxiconazol & 1,00 & + & + & + \\
\hline $\mathrm{P} 0,20$ & Piraclostrobina & 0,20 & + & - & - \\
\hline $\mathrm{P} 0,30$ & Piraclostrobina & 0,30 & - & + & + \\
\hline $\mathrm{P} 0,40$ & Piraclostrobina & 0,40 & + & + & + \\
\hline $\mathrm{P} 0,50$ & Piraclostrobina & 0,50 & - & + & + \\
\hline P0,60 & Piraclostrobina & 0,60 & + & - & - \\
\hline $\mathrm{P} 0,80$ & Piraclostrobina & 0,80 & + & - & - \\
\hline СТ0,40 & Carboxina + tiram & 0,40 & - & + & + \\
\hline CT1,00 & Carboxina + tiram & 1,00 & + & - & - \\
\hline $\mathrm{AC}$ & Azoxistrobina + ciproconazol & 0,30 & + & - & - \\
\hline PPZ & Propiconazol & 0,625 & - & + & + \\
\hline
\end{tabular}

${ }^{1}$ Presença (+) e Ausência (-); ${ }^{2}$ Testemunhas. 


\section{RESULTADOS E DISCUSSÃO}

Os resultados das análises de variância (Teste F) dos três ensaios mostraram que houve efeito significativo entre tratamentos para todas as variáveis (Tabelas 3 a 5). Em casa de vegetação, comparando-se T1 com T2, nota-se que a infestação do substrato reduziu a brotação em $48 \%$ no primeiro ensaio (Tabela 3) e em 44\% no segundo (Tabela 4), percentuais que estão em conformidade com BEGUM et al. (2008). No primeiro ensaio, a infestação também reduziu em $67 \%$ a massa fresca da parte aérea e em $66 \%$ a de raízes (Tabela 3), enquanto que, no segundo, essas variáveis não foram significativamente afetadas (Tabela 4).

O ataque da doença foi mais severo no primeiro ensaio, provavelmente devido às temperaturas ocorridas durante sua condução, que foram, em média, $2,6^{\circ} \mathrm{C}$ mais baixas do que as registradas no segundo. De acordo com CLEMENTS (1940), temperaturas abaixo de $21^{\circ} \mathrm{C}$ atrasam ou inibem a brotação da cana-de-açúcar; acima de $21^{\circ} \mathrm{C}$, a brotação aumenta progressivamente (DILLEWIJN, 1948). Como o fator preponderante para manifestação da podridão abacaxi é o retardamento da brotação, temperaturas mais baixas aumentam a intensidade da doença (RAID, 2012). Ademais, segundo KUO et al. (1969), T. paradoxa produz maiores quantidades do gás fitotóxico acetato de etila em baixas temperaturas,

Tabela 3 - Efeito da pulverização de fungicidas em rebolos de cana-de-açúcar no controle da podridão abacaxi em casa de vegetação (primeiro ensaio, ano 2008).

\begin{tabular}{llcc}
\hline Tratamentos & $\begin{array}{c}\text { Brotação } \\
(\%)\end{array}$ & $\begin{array}{c}\text { Massa fresca } \\
\text { da parte } \\
\text { aérea (g) }\end{array}$ & $\begin{array}{c}\text { Massa fresca } \\
\text { de raízes (g) }\end{array}$ \\
\hline T1 & 46 & 18,8 & 15,2 \\
T2 & $88^{*}$ & $56,8^{*}$ & $44,7^{*}$ \\
PE0,25 & 50 & 38,2 & 28,0 \\
PE0,50 & 67 & 51,9 & 26,6 \\
PE0,75 & $88^{*}$ & 43,5 & 28,0 \\
PE1,00 & $71^{*}$ & 43,5 & 19,8 \\
P0,20 & 58 & 41,5 & 16,4 \\
P0,40 & $71^{*}$ & 49,4 & 23,4 \\
P0,60 & $75^{*}$ & $61,2^{*}$ & $34,6^{*}$ \\
P0,80 & 67 & $64,3^{*}$ & $31,3^{*}$ \\
CT1,00 & $17^{*}$ & 22,0 & 15,8 \\
AC & 58 & 27,5 & 17,8 \\
CV (\%) & 19,14 & 37,87 & 25,25 \\
Teste F & P<0,01 & P<0,01 & P $<0,01$ \\
\hline
\end{tabular}

*Tratamento que difere estatisticamente da testemunha (T1), segundo Teste de Dunnett a 5\% de significância.
Tabela 4 - Efeito da pulverização de fungicidas em rebolos de cana-de-açúcar no controle da podridão abacaxi em casa de vegetação (segundo ensaio, ano 2009).

\begin{tabular}{llcl}
\hline Tratamentos & $\begin{array}{c}\text { Brotação } \\
(\%)\end{array}$ & $\begin{array}{c}\text { Massa fresca da } \\
\text { parte aérea (g) }\end{array}$ & $\begin{array}{l}\text { Massa fresca } \\
\text { de raízes (g) }\end{array}$ \\
\hline T1 & 42 & 103,1 & 60,8 \\
T2 & $75^{*}$ & 120,2 & 87,3 \\
PE0,60 & 67 & 117,3 & 84,4 \\
PE0,80 & $75^{*}$ & 137,8 & 95,6 \\
PE1,00 & $79^{*}$ & $155,0^{*}$ & 103,4 \\
P0,30 & $75^{*}$ & 142,6 & 95,7 \\
P0,40 & $83^{*}$ & 147,9 & $118,5^{*}$ \\
P0,50 & $88^{*}$ & $162,7^{*}$ & $116,6^{*}$ \\
CT0,40 & 50 & 122,5 & 107,6 \\
PPZ & $75^{*}$ & 152,5 & $124,7^{*}$ \\
CV (\%) & 21,26 & 18,06 & 25,16 \\
Teste F & $\mathrm{P}<0,01$ & $0,01<\mathrm{P}<0,05$ & $0,01<\mathrm{P}<0,05$ \\
\hline
\end{tabular}

* Tratamento que difere estatisticamente da testemunha (T1), segundo Teste de Dunnett a 5\% de significância.

o que, aliado à brotação mais lenta, explica a maior agressividade do patógeno no primeiro ensaio.

Os resultados do primeiro ensaio em casa de vegetação são mostrados na tabela 3 . Dentre os tratamentos, o que mais se destacou foi P0,60, pois superou T1 em todas as variáveis. O tratamento $\mathrm{P} 0,80$ proporcionou maiores massas frescas da parte aérea e de raízes, porém não diferiu estatisticamente de T1 para brotação. Outros tratamentos com algum efeito contra a doença foram PE0,75, PE1,00 e P0,40, todos com brotação superior à T1. A pulverização de fungicidas aumentou a brotação em até $91 \%$ (PE0,75), a massa fresca da parte aérea em até $242 \%(\mathrm{P} 0,80)$ e a massa fresca de raízes em até 128\% (P0,60), em comparação às parcelas não tratadas (T1).

Considerando o segundo ensaio (Tabela 4), o tratamento P0,50 foi o mais eficiente, sendo superior à T1 para brotação, massa fresca da parte aérea e de raízes. P0,40 e PPZ apresentaram aumentos na brotação e na massa fresca de raízes, porém não diferiram de T1 para massa fresca da parte aérea. Outro tratamento que se destacou foi PE1,00, com incrementos na brotação e na massa fresca da parte aérea. PE0,80 e P0,30 também apresentaram algum efeito contra a doença, pois foram superiores à T1 para brotação. O tratamento dos rebolos aumentou a brotação em até $110 \%$ (P0,50), a massa fresca da parte aérea em até 58\% $(\mathrm{P} 0,50)$ e a massa fresca de raízes em até $105 \%$ (PPZ), em comparação à T1.

Os resultados mostrados por alguns tratamentos indicam que a pulverização dos rebolos 
Tabela 5 - Efeito da pulverização de fungicidas em rebolos de cana-de-açúcar no controle da podridão abacaxi e em variáveis agroindustriais no campo.

\begin{tabular}{|c|c|c|c|c|c|}
\hline Tratamentos & Plantas $\mathrm{m}^{-1}$ & $\begin{array}{c}\text { Massa fresca da parte } \\
\text { aérea }\left(\mathrm{t} \mathrm{ha}^{-1}\right)\end{array}$ & TCH (t ha $\left.{ }^{-1}\right)$ & ATR (kg ha $\left.{ }^{-1}\right)$ & TAH (t ha $\left.{ }^{-1}\right)$ \\
\hline $\mathrm{T} 1$ & 6,0 & 1,6 & 121,2 & 135,5 & 16,4 \\
\hline PE0,60 & $7,0^{*}$ & 1,9 & 130,5 & 133,7 & 17,4 \\
\hline PE0,80 & $6,9^{*}$ & 1,8 & $133,1^{*}$ & 137,6 & $18,3^{*}$ \\
\hline PE1,00 & $7,1^{*}$ & 1,8 & $133,7^{*}$ & 137,0 & $18,3^{*}$ \\
\hline $\mathrm{P} 0,30$ & 6,7 & $2,2^{*}$ & 127,8 & 127,3 & 16,3 \\
\hline $\mathrm{P} 0,40$ & 6,6 & 1,7 & 129,9 & $123,9^{*}$ & 16,1 \\
\hline P0,50 & $7,0^{*}$ & 1,8 & 127,9 & 133,1 & 17,0 \\
\hline СТ0,40 & 6,1 & 1,8 & 124,6 & 133,8 & 16,7 \\
\hline PPZ & $7,0^{*}$ & 1,7 & $133,8^{*}$ & 133,1 & 17,8 \\
\hline CV (\%) & 6,43 & 17,32 & 3,87 & 3,45 & 5,11 \\
\hline Teste F & $\mathrm{P}<0,01$ & $0,01<\mathrm{P}<0,05$ & $0,01<\mathrm{P}<0,05$ & $\mathrm{P}<0,01$ & $\mathrm{P}<0,01$ \\
\hline
\end{tabular}

* Tratamento que difere estatisticamente da testemunha (T1), segundo Teste de Dunnett a 5\% de significância.

tem potencial no controle da podridão abacaxi. Dados semelhantes foram obtidos por RAID (1990), na variedade suscetível CP74-2005, em casa de vegetação; dos nove tratamentos fungicidas, todos foram estatisticamente superiores à testemunha para brotação, variável escolhida pelo autor para avaliação indireta da doença.

Na tabela 5, são apresentados os resultados do ensaio de campo. Dos tratamentos estudados, destacaram-se PE0,80 e PE1,00, que, além de proporcionarem maior número de plantas $\mathrm{m}^{-1}$ em relação à T1, também foram superiores em TCH e TAH. Resultados semelhantes foram obtidos por PPZ; porém, este não diferiu de T1 para TAH. PE0,60 e P0,50 também apresentaram efeito contra o patógeno, aumentando o número de plantas $\mathrm{m}^{-1}$, porém não diferiram de T1 para as demais variáveis. A pulverização dos rebolos proporcionou incrementos de até $18 \%$ no número de plantas $\mathrm{m}^{-1}(\mathrm{PE} 1,00)$ e de até $37,5 \%$ na massa fresca da parte aérea, aos 90 dias após o plantio (P0,30). Além disso, foram observados aumentos de até $10 \%$ para TCH (PPZ) e de até 12\% para TAH (PE0,80 e PE1,00).

A análise conjunta dos dados deste trabalho indica que a pulverização de determinados fungicidas em rebolos foi eficiente no controle da podridão abacaxi. COMSTOCK et al. (1984), testando métodos de aplicação do fungicida propiconazol no campo, obtiveram incrementos na brotação e plantas com melhor desenvolvimento inicial, em comparação à testemunha e à outros fungicidas. Os autores consideraram a brotação como a melhor maneira de quantificar a doença indiretamente.

RAID et al. (1990) e RAID (1991), utilizando a variedade suscetível CP74-2005, obtiveram aumentos no número de plantas $\mathrm{m}^{-1}$, em
TCH e TAH com a aplicação do propiconazol no campo, tanto com a imersão dos rebolos na calda, como com a pulverização deles. Segundo RAID (1990), no caso da pulverização, a atenção com a cobertura na região do corte dos rebolos deve ser redobrada, pois é nessa região em que normalmente se iniciam as infecções pela podridão abacaxi. Já FERREIRA et al. (2008) observaram que a pulverização do fungicida fluazinam, por meio de um sistema conjugado à plantadora mecanizada, proporcionou recuperação de até $15 \%$ na produtividade, em comparação às parcelas não tratadas.

\section{CONCLUSÃO}

O presente estudo demonstra o potencial de danos de T. paradoxa na cultura da cana-de-açúcar, e que medidas de controle devem ser colocadas em prática em situações que favoreçam o patógeno quando variedades suscetíveis são utilizadas.

O controle da podridão abacaxi da canade-açúcar por meio da pulverização de rebolos no sulco de plantio mostrou-se eficaz com os seguintes fungicidas: piraclostrobina + epoxiconazol; propiconazol; e piraclostrobina. Este último, apesar de não ter apresentado ganhos significativos em TCH e TAH, mostrou bons resultados no controle da doença em casa de vegetação, aumentando a brotação e proporcionando plantas mais vigorosas.

\section{REFERÊNCIAS}

BEGUM, F. et al. Effect of pineapple disease on germination and yield contributing parameters of some promising varieties of sugarcane. 
Sugar Technology, v.10, p.171-173, 2008. Disponível em: <http:// link.springer.com/article/10.1007\%2Fs12355-008-0031-z>. Acesso em: 26 fev. 2013. doi: 10.1007/s12355-008-0031-z.

CIIAGRO. Centro Integrado de Informações Agrometeorológicas. São Paulo: Portal do Governo do Estado de São Paulo, 2013. Acesso em: 07 mar. 2013. Online. Disponível em: <http://www.ciiagro. sp.gov.br>.

CLEMENTS, H.F. Factors affecting the germination of sugarcane. Hawaiian Planter's Record, v.44, p.117-146, 1940.

COMSTOCK, J.C. et al. Control of pineapple disease of sugarcane with Propiconazole. Plant Disease, v.68, p.1072-1075, 1984.

CONAB. Acompanhamento da safra brasileira: cana-deaçúcar, safra 2012/2013, terceiro levantamento, dezembro/2012. Brasília: CONAB 2012, 2012. 18p. Acesso em: 06 mar. 2013. Online. Disponível em: <http://www.conab.gov.br/OlalaCMS/ uploads/arquivos/12_12_12_10_34_43_boletim_cana_ portugues_12_2012.pdf $>$.

CONAB. Acompanhamento da safra brasileira: cana-deaçúcar, safra 2011/2012, terceiro levantamento, dezembro/2011. Brasília : CONAB 2011, 2011. 20p. Acesso em: 06 mar. 2013. Online. Disponível em: <http://www.conab.gov.br/OlalaCMS/ uploads/arquivos/11_12_08_11_00_54_08.pdf>.

DILLEWIJN, C.V. The germination of sugarcane. Sugar Journal v.10, p.20-23, 1948 .

FERREIRA, M.C. et al. Tratamento de toletes de cana-deaçúcar para controle da podridão-abacaxi em pulverização conjugada ao plantio mecanizado. Engenharia Agrícola, v.28, p.263-273, 2008. Disponível em: <http://www.scielo.br/scielo. php?script=sci_arttext\&pid=S0100-69162008000200007\&lng =pt\&nrm=iso $>$. Acesso em: 26 fev. 2013. doi: 10.1590/S010069162008000200007

GHELLER, A.C.A. et al. Características agronômicas: variedades RB. Araras: Departamento de Biotecnologia Vegetal, 2002. 23p. (Boletim Técnico).

GHELLER, A.C.A. et al. Manual de método alternativo para medição da produção de cana-de-açúcar. Araras: Departamento de Biotecnologia Vegetal, 1999. 13p. (Boletim Técnico).
HILTON, H.M. et al. Benomyl seedpiece treatment for sugarcane and its analysis. Hawaiian Planter's Record, v.58, p.159-164, 1971.

KUO, T.T. et al. Ethyl acetate produced by Ceratocystis paradoxa and $\boldsymbol{C}$. adiposum and its role in inhibition of germination of sugarcane buds. Canadian Journal of Botany, v.47, p.14591463, 1969.

MOUTIA, Y.; SAUMTALLY, S. Detection from soil and distribution of Ceratocystis paradoxa Moreau, causal agent of the pineapple disease of sugarcane. In: ANNUAL MEETING OF AGRICULTURAL SCIENTISTS, 4., 1999, Reduit, Mauritius. Anais... Reduit: AMAS, 1999. p.75-82. Acesso em: 4 mar. 2013. Online. Disponível em: <http://www.gov.mu/portal/sites/ncb/ moa/farc/amas99/s24.pdf>.

OERKE, E.-C. Crop losses to pests. Journal of Agricultural Science, v.144, p.31-43, 2006. Disponível em: <http://journals. cambridge.org/action/displayFulltext?type $=6 \&$ fid $=431726 \& j i d=$ AGS\&volumeId=144\&issueId=01\&aid=431724\&bodyId=\&mem bershipNumber=\&societyETOCSession=\&fulltextType=RV\&fileId=S0021859605005708 > . Acesso em: 26 fev. 2013. doi: 10.1017/ S0021859605005708.

RAID, R.N. Fungicidal control of pineapple disease of sugarcane. Journal of the American Society Sugar Cane Technologists, v.10, p.45-50, 1990 .

RAID, R.N. Pineapple disease of sugarcane. Flórida: University of Florida, 2012. 2p. Acesso em: 07 mar. 2013. Online. Disponível em: <http://edis.ifas.ufl.edu/pdffiles/SC/SC00500.pdf $>$.

RAID, R.N. et al. Influence of seedpiece treatment and seeding density on stalk population and yield of a pineapple disease susceptible sugarcane cultivar. Journal of the American Society Sugar Cane Technologists, v.11, p.13-17, 1991.

SERAFIM, L.G.F. Influência do plantio mecanizado no índice de brotação da cana-de-açúcar. STAB, v.31, p.24-28, 2013.

YADAHALLI, K.B. et al. Standardization of inoculation techniques for Ceratocystis paradoxa - an incitant of sugarcane sett rot. Indian Phytopathology, v.60, p.377-379, 2007. 